\title{
Comparison the sixth and seventh editions of the AJCC staging system for T1 gastric cancer: a long-term follow-up study of 2124 patients
}

\author{
Kyung Hak Choi ${ }^{1} \cdot$ Byung Sik Kim $^{1} \cdot$ Seong Tae $\mathrm{Oh}^{1} \cdot$ Jeong Hwan Yook $^{1} \cdot$ \\ Beom Su Kim ${ }^{1}$
}

Received: 26 August 2015/Accepted: 21 December 2015/Published online: 5 January 2016

(c) The International Gastric Cancer Association and The Japanese Gastric Cancer Association 2016

\begin{abstract}
Background/Aim The aim of this study was to establish an appropriate TNM staging system for early gastric cancer.

Methodology We evaluated 2124 patients who had undergone gastrectomy for early gastric cancer between 1989 and 2001.

Results Using the seventh edition of the American Joint Committee on Cancer (AJCC) staging system, we found no significant differences in tumor recurrence and survival between $\mathrm{N} 1$ and $\mathrm{N} 2$ cancers or between $\mathrm{N} 3 \mathrm{a}$ and $\mathrm{N} 3 \mathrm{~b}$ cancers, whereas the survival curves for $\mathrm{N} 2$ and N3 cancers were quite different. Similarly, using the classification in the sixth edition of the AJCC staging system, we found no significant difference in survival between the N2 and N3 cancer groups, whereas the survival curves for $\mathrm{N} 1$ versus $\mathrm{N} 2$ or N3 cancers were quite different.

Conclusions The classifications in the sixth and seventh editions of the AJCC staging system have a limitation for $\mathrm{T} 1$ gastric cancer (early gastric cancer).
\end{abstract}

Keywords Early gastric cancer - Nodal stage · TNM

Electronic supplementary material The online version of this article (doi:10.1007/s10120-015-0590-0) contains supplementary material, which is available to authorized users.

Beom Su Kim

bskim0251@naver.com

1 Department of Surgery, Asan Medical Center, University of Ulsan College of Medicine, 88, Olympic-ro 43-gil, Songpa$\mathrm{Gu}$, Seoul 05505, Korea

\section{Introduction}

Early gastric cancers (EGCs; T1 cancer) make up more than $50 \%$ of all gastric cancers $[1,2]$. The survival rate of patients with EGC exceeds $90 \%$ in Japan $[3,4]$ and in Western countries [5]. Variable rates of recurrence of EGC have been reported in these countries, ranging from 2.1 to $12.4 \%$ [6-8]. The seventh edition of the American Joint Committee on Cancer (AJCC) staging system was published in 2010. However, this new AJCC TNM staging stystem is inadequate for EGC but is appropriate for advanced gastric cancer [9]. In patients with EGC, survival is affected by the presence of invaded lymph nodes not by the depth of penetration of the lesion or its size [10]. Therefore, the aims of this study were to evaluate tumor recurrence and long-term survival of patients with EGC in relation to the AJCC TNM staging system on the basis of the results of a large-scale study with long-term follow-up and to recommend a new TNM staging system.

\section{Methods}

We collected data on 8685 patients who had undergone surgery for gastric cancer from the databases and electronic medical records at Asan Medical Center, University of Ulsan College of Medicine, Seoul, Korea, between 1989 and December 2001. Of those patients, we retrospectively evaluated 2124 patients who had undergone curative gastrectomy for EGC (mucosal or submucosal). Figure 1 shows the data analysis flow diagram for this study. Clinicopathological characteristics and macroscopic findings were analyzed in accordance with the Japanese Classification of Gastric Cancer [11]. 


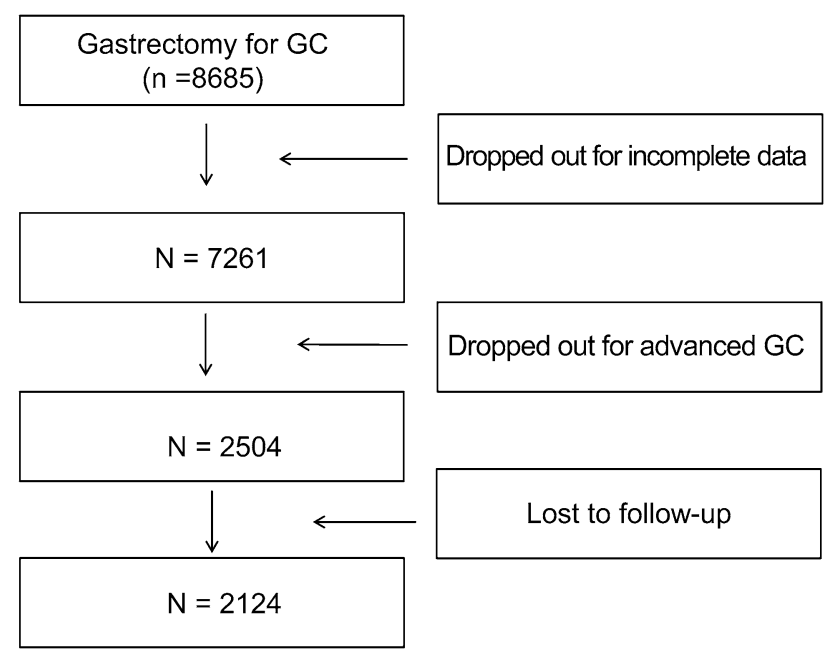

Fig. 1 Data analysis flow diagram for this study. $G C$ gastric cancer

We reviewed tumor recurrence patterns and prognosis of the patients undergoing gastrectomy for EGC, and related the results to the sixth and seventh editions of the AJCC staging system. We reclassified nodal stages to achieve appropriate staging for $\mathrm{T} 1$ gastric cancer: $\mathrm{N} 1$ as one to five lymph node metastases, $\mathrm{N} 2$ as six to ten lymph node metastases, and N3 as more than ten lymph node metastases.

We evaluated the categorical variables using the chisquare test and continuous variables using the Student $t$ test. We evaluated the univariate risk factors for tumor recurrence using log-rank tests and evaluated multivariate risk factors using a Cox regression model, the hazard ratios, and the $95 \%$ confidence intervals. The $C$ index was evaluated to determine whether the most recent AJCC TNM staging system is suitable or not suitable for discrimination. The $95 \%$ confidence intervals for the $C$ index were obtained through the percentile bootstrap method (1000 replicates) [12]. Survival curves after tumor recurrence and recurrence probability curves after surgery were evaluated by the Kaplan-Meier method. All statistical analyses were performed with Statistical Package for the Social Sciences Windows version 19.0 (SPSS, Chicago, IL, USA). Significance was set at $p<0.05$.

This study received institutional review board approval (protocol number 2012-0032).

\section{Results}

The general clinicopathological characteristics of the study cohort are summarized in Table 1. There were 1399 male patients $(65.9 \%)$ and 725 female patients $(34.1 \%)$. The mean follow-up period was $152.1 \pm 52.6$ months. Two hundred fifty-six patients $(12.1 \%)$ had lymph node metastases. Ninety-seven patients $(4.6 \%)$ experienced tumor recurrence during the follow-up period: there was hematogenous recurrence in 41 patients, lymphatic recurrence in 11 patients, locoregional recurrence in 12 patients, peritoneal recurrence in 13 patients, and remnant stomach recurrence in 20 patients. Multiple synchronous EGC lesions were detected in 76 patients $(3.6 \%)$ at the time of surgery. Patients with recurrence had deeper invasion, more frequent excavated gross findings, more lymph node involvement, and more lymphovascular invasion than patients without recurrence.

\section{Risk factors for tumor recurrence and prognostic factors}

Depth of invasion, macroscopic findings, and microscopic lymphovascular invasion were risk factors in univariate analysis, and depth of invasion and lymph node metastasis were independent risk factors for tumor recurrence in the multivariate analysis $(p<0.05)$. In addition, lymph node metastasis has a larger hazard ratio than the depth of invasion. The results of univariate and multivariate analyses of prognostic factors for disease-related death are summarized in Table 2. Lymph node metastasis is the only independent prognostic factor in the Cox regression model.

\section{Correlation with the seventh edition of the AJCC staging system}

Table 3 shows tumor recurrence and survival according to the seventh edition of the AJCC cancer staging system. There were no significant differences in tumor recurrence and survival between the $\mathrm{N} 1$ (one or two nodes involved) and N2 (three to six nodes involved), N3a (7 to 15 nodes involved), or N3b (more than 15 nodes involved) cancer groups or between the $* \mathrm{~N} 1$ (only one node involved) and $\mathrm{N} 2$ cancer groups $(p>0.05)$. Figure 2 shows the diseaserelated survival curve of patients according to the seventh edition of the AJCC staging system. There was no significant difference between N1 (stage IB) and N2 (stage IIA) cancer groups, but there was a marked difference in survival between N2 and N3 (stage IIB) cancer groups.

\section{Correlation with the sixth edition of the AJCC staging system}

The results of analyses of tumor recurrence and survival according to the sixth edition of the AJCC staging system are summarized in Table 3 . There were significant differences in tumor recurrence between nodal stages $(p<0.05)$. However, there was no significant difference in survival between the N2 and N3 cancer groups $(p>0.05)$. Figure $2 \mathrm{~b}$ presents the disease-related survival curves of the 
Table 1 Clinicopathological characteristics for nonrecurrence and recurrence

\begin{tabular}{|c|c|c|c|c|}
\hline Characteristic & All patients & $\begin{array}{l}\text { Nonrecurrence } \\
(n=2027)\end{array}$ & $\begin{array}{l}\text { Recurrence } \\
(n=97)\end{array}$ & $p$ \\
\hline Sex & & & & NS \\
\hline Male & $1399(65.9 \%)$ & $1367(66.0 \%)$ & $62(63.9 \%)$ & \\
\hline Female & $725(34.1 \%)$ & $690(34.0 \%)$ & $32(36.1 \%)$ & \\
\hline Age (years) & $54.8 \pm 11.5$ & $54.7 \pm 11.5$ & $56.4 \pm 11.8$ & NS \\
\hline Follow-up (months) & $151.8 \pm 52.7$ & $155.4 \pm 49.6$ & $79.0 \pm 59.0$ & $<0.001$ \\
\hline Location of tumor & & & & NS \\
\hline Lower third & $1298(61.1 \%)$ & $1242(61.3 \%)$ & $56(57.7 \%)$ & \\
\hline Middle third & $640(30.1 \%)$ & $607(29.9 \%)$ & $33(34.0 \%)$ & \\
\hline Upper third & $188(8.8 \%)$ & $178(8.8 \%)$ & $6(8.2 \%)$ & \\
\hline Tumor size (mm) & $30.5 \pm 19.1$ & $30.4 \pm 19.1$ & $32.7 \pm 17.1$ & NS \\
\hline Gastrectomy & & & & NS \\
\hline Subtotal & $1886(88.8 \%)$ & $1801(88.9)$ & $85(87.6 \%)$ & \\
\hline Total & $238(11.2 \%)$ & $226(11.1)$ & $12(12.4 \%)$ & \\
\hline Depth of invasion & & & & $<0.001$ \\
\hline Mucosa & $1054(49.6 \%)$ & $1029(50.8 \%)$ & $25(25.8 \%)$ & \\
\hline Submucosa & $1070(50.4 \%)$ & $998(49.2 \%)$ & $72(74.2 \%)$ & \\
\hline Macroscopic finding & & & & 0.025 \\
\hline Superficial & $1783(83.9 \%)$ & $1711(84.4 \%)$ & $72(74.2 \%)$ & \\
\hline Protruded & $122(5.7 \%)$ & $114(5.6 \%)$ & $8(8.2 \%)$ & \\
\hline Excavated & $219(10.3 \%)$ & $202(10.0 \%)$ & $17(17.5 \%)$ & \\
\hline Histological type & & & & NS \\
\hline Differentiated & $1090(51.3 \%)$ & $1043(51.5 \%)$ & $47(48.5 \%)$ & \\
\hline Undifferentiated & $1034(48.7 \%)$ & $984(48.5 \%)$ & $50(51.5 \%)$ & \\
\hline Lymph node metastasis & & & & $<0.001$ \\
\hline No & $1868(87.9 \%)$ & $1816(89.6 \%)$ & $52(53.6 \%)$ & \\
\hline Yes & $256(12.1 \%)$ & $211(10.4 \%)$ & $45(46.4 \%)$ & \\
\hline Lymphatic/venous invasion & & & & $<0.001$ \\
\hline No & $1925(90.6 \%)$ & $1852(91.4 \%)$ & $73(75.3 \%)$ & \\
\hline Yes & $199(9.4 \%)$ & $175(8.6 \%)$ & $24(24.7 \%)$ & \\
\hline Retrieved lymph nodes & $24.7 \pm 12.7$ & $24.8 \pm 12.7$ & $24.3 \pm 12.9$ & NS \\
\hline Multiple cancers & & & & NS \\
\hline No & $2048(96.4 \%)$ & $1954(96.4 \%)$ & $94(96.9 \%)$ & \\
\hline Yes & $76(3.6 \%)$ & $73(8.6 \%)$ & $4(3.1 \%)$ & \\
\hline
\end{tabular}

NS nonspecific patients according to the classification in the sixth edition of the AJCC staging system. The survival curves for N1 cancer patients versus $\mathrm{N} 2$ or $\mathrm{N} 3$ cancer patients were quite different.

\section{Correlation with the new recommended TNM staging system}

Table 4 shows tumor recurrences and survival rates according to our recommended TNM staging system. There are significant differences in tumor recurrence between $\mathrm{N} 0$ and $\mathrm{N} 1$ cancers, $\mathrm{N} 1$ and $\mathrm{N} 2$ cancers, and $\mathrm{N} 2$ and N3 cancers $(p<0.05)$. Figure $2 \mathrm{c}$ shows the survival curves of the patients according to our nodal stages. There are significant differences in survival between $\mathrm{N} 0$ and $\mathrm{N} 1$ cancers, $\mathrm{N} 1$ and $\mathrm{N} 2$ cancers, and $\mathrm{N} 2$ and $\mathrm{N} 3$ cancers $(p<0.05)$. Furthermore, the differences between the survival curves are evenly distributed.

Table 5 shows the calculated $C$ index for each individual staging system. There is no significant difference in the $C$ index 
Table 2 Prognostic factors based on log-rank tests and a Cox regression model
Table 3 Recurrence and survival based on the KaplanMeier method using the logrank test, according to the sixth and seventh editions of the American Joint Committee on Cancer (AJCC) staging system

\begin{tabular}{|c|c|c|c|c|c|}
\hline \multirow[t]{2}{*}{ Characteristic } & \multirow[t]{2}{*}{ Number } & \multicolumn{2}{|c|}{ Univariate analysis } & \multicolumn{2}{|c|}{ Multivariate analysis } \\
\hline & & Number & $p$ & Hazard ratio $^{\mathrm{a}}$ & $p$ \\
\hline Age (years) & & & 0.046 & & \\
\hline$\leq 55$ & 1042 & $36(3.5 \%)$ & & & \\
\hline$>55$ & 1088 & $53(4.9 \%)$ & & $1.54(0.98-2.32)$ & NS \\
\hline Depth of invasion & & & $<0.001$ & & \\
\hline Mucosa & 1054 & $22(2.1 \%)$ & & & \\
\hline Submucosa & 1070 & $66(6.1 \%)$ & & $1.35(0.79-2.30)$ & NS \\
\hline Macroscopic findings & & & 0.013 & & \\
\hline Superficial & 1783 & $65(3.6 \%)$ & & & \\
\hline Protruded & 122 & $8(6.5 \%)$ & & $1.14(0.54-2.41)$ & NS \\
\hline Excavated & 219 & $16(7.3 \%)$ & & $1.42(0.82-2.48)$ & NS \\
\hline Lymph node metastasis & & & $<0.001$ & & \\
\hline No & 1868 & $41(4.7 \%)$ & & & \\
\hline Yes & 256 & $48(18.7 \%)$ & & $7.41(4.63-11.86)$ & $<0.001$ \\
\hline Lymphatic/venous invasion & & & $<0.001$ & & \\
\hline No & 1925 & $64(3.3 \%)$ & & & \\
\hline Yes & 199 & $25(12.6 \%)$ & & $1.65(0.97-2.74)$ & NS \\
\hline
\end{tabular}

NS nonspecific

a The $95 \%$ confidence interval is given in parentheses

\begin{tabular}{|c|c|c|c|c|c|}
\hline \multirow[t]{2}{*}{ Characteristics } & \multirow{2}{*}{$\begin{array}{l}\text { Number } \\
(n=2124)\end{array}$} & \multicolumn{2}{|l|}{ Tumor recurrence } & \multicolumn{2}{|c|}{ Disease-related death } \\
\hline & & Number & $p$ & Survival rate $(\%)$ & $p$ \\
\hline \multicolumn{6}{|c|}{ AJCC staging system, 7th edition } \\
\hline N0 vs N1 & 1868 vs 156 & $52(2.8 \%)$ vs $18(11.5 \%)$ & $<0.001$ & 97.8 vs 85.9 & $<0.001$ \\
\hline $\mathrm{N} 1$ vs $\mathrm{N} 2$ & 156 vs 75 & $18(11.5 \%)$ vs $8(10.7 \%)$ & NS & 85.9 vs 90.7 & NS \\
\hline $\mathrm{N} 1$ vs N3 & 156 vs 25 & $18(11.5 \%)$ vs $19(76.0 \%)$ & $<0.001$ & 85.9 vs 24.0 & $<0.001$ \\
\hline $\mathrm{N} 2$ vs N3 & 75 vs 25 & $8(10.7 \%)$ vs $19(76.0 \%)$ & $<0.001$ & 90.7 vs 24.0 & $<0.001$ \\
\hline $\mathrm{N} 3 \mathrm{a}$ vs N3b & 20 vs 5 & $14(70.0 \%)$ vs $5(100.0 \%)$ & NS & 30.0 vs 0.0 & NS \\
\hline \multicolumn{6}{|c|}{ AJCC staging system, 6th edition } \\
\hline N0 vs N1 & 1868 vs 231 & $52(2.8 \%)$ vs $26(25.9 \%)$ & $<0.001$ & 97.8 vs 87.4 & $<0.001$ \\
\hline $\mathrm{N} 1$ vs N2 & 231 vs 20 & $26(25.9 \%)$ vs $14(70.0 \%)$ & $<0.001$ & 87.4 vs 30.0 & $<0.001$ \\
\hline $\mathrm{N} 1$ vs N3 & 1868 vs 5 & $52(2.8 \%)$ vs $14(70.0 \%)$ & $<0.001$ & 87.4 vs 0.00 & $<0.001$ \\
\hline $\mathrm{N} 2$ vs $\mathrm{N} 3$ & 20 vs 5 & $14(70.0 \%)$ vs $5(100.0 \%)$ & NS & 30.0 vs 0.00 & NS \\
\hline
\end{tabular}

$N S$ nonspecific

\section{Discussion}

Lymph node metastasis is a significant risk factor for EGC recurrence and the most valuable prognostic factor for EGC [13-15]. Early tumor recurrence has been associated with lymph node metastasis and a poor prognosis [7, 16, 17]. In our study we observed that tumor recurrence and prognosis of T1a (tumor invades mucosa) cancer were similar to those for T1b (tumor invades submucosa) cancer $(p>0.05)$, and we identified lymph node metastasis as an independent risk factor for tumor recurrence, as well as an independent prognostic factor. This result shows that $\mathrm{T} 1$ cancer (EGC) stages mostly depend on nodal status.

More than $50 \%$ of all gastric cancers are diagnosed as T1 (invading the mucosa or submucosa) cancers, and early detection of gastric cancer is increasing steadily. However, the classification in the seventh edition of the AJCC staging system is based on advanced gastric cancer [9], and treatment modalities and survival predictions have followed the AJCC TNM staging system. So far, there has been no report focusing on a TNM staging system for T1 cancer. Therefore, we investigated tumor recurrence and survival 

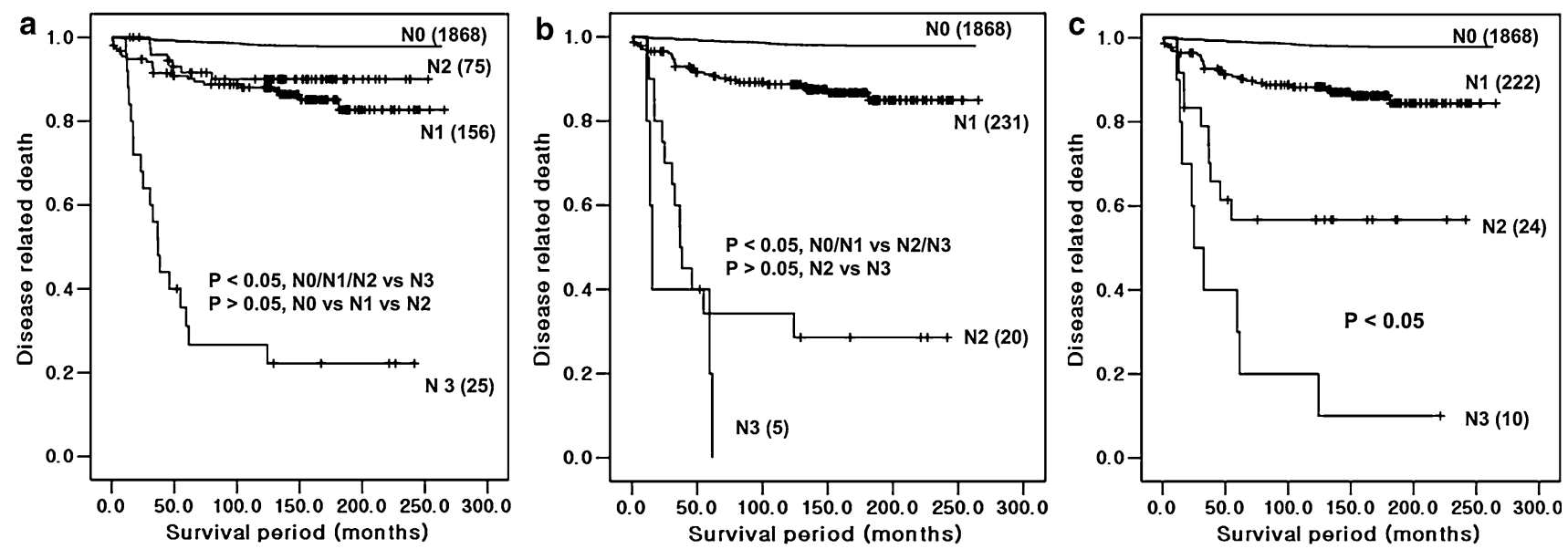

Fig. 2 Survival by nodal stage. a There was no significant difference between $\mathrm{N} 1$ and $\mathrm{N} 2$ cancers in the seventh edition of the American Joint Committee on Cancer staging system. b There was no significant difference between $\mathrm{N} 2$ and $\mathrm{N} 3$ cancers in the sixth edition of the American Joint Committee on Cancer staging system. c Survival as defined by the proposed new nodal staging system.
There were significant differences between N0 and N1 cancers, N1 and $\mathrm{N} 2$ cancers, and $\mathrm{N} 2$ and $\mathrm{N} 3$ cancers $(p<0.05)$; N1 corresponds to one to five lymph node metastases, N2 corresponds to six to ten lymph node metastases, and N3 corresponds to more than ten lymph node metastases
Table 4 Recurrence and survival based on the KaplanMeier method using the logrank test, according to the recommended nodal stages

\begin{tabular}{|c|c|c|c|c|c|}
\hline \multirow[t]{2}{*}{ Characteristic } & \multirow{2}{*}{$\begin{array}{l}\text { Number } \\
(n=2124)\end{array}$} & \multicolumn{2}{|l|}{ Tumor recurrence } & \multicolumn{2}{|c|}{ Disease related death } \\
\hline & & Number & $p$ & Survival rate $(\%)$ & $p$ \\
\hline N0 vs N1 & 1868 vs 222 & $52(2.8 \%)$ vs $26(11.7 \%)$ & $<0.001$ & 97.8 vs 86.9 & $<0.001$ \\
\hline $\mathrm{N} 1$ vs N2 & 222 vs 24 & $26(11.7 \%)$ vs $10(41.6 \%)$ & $<0.001$ & 86.8 vs 58.3 & $<0.001$ \\
\hline N1 vs N3 & 222 vs 10 & $26(11.7 \%)$ vs $9(90.0 \%)$ & $<0.001$ & 86.9 vs 10.0 & $<0.001$ \\
\hline N2 vs N3 & 24 vs 10 & $10(41.6 \%)$ vs $9(90.0 \%)$ & 0.012 & 58.3 vs 10.0 & 0.014 \\
\hline
\end{tabular}

Table $5 C$ index determined through the percentile bootstrap method (1000 replicates)

\begin{tabular}{llll}
\hline$C$ index & Recurrence & Death & Related death \\
\hline AJCC staging system, 6th edition & $0.6992(0.6475-0.7510)$ & $0.5611(0.5415-0.5807)$ & $0.7310(0.6774-0.7846)$ \\
AJCC staging system, 7th edition & $0.6994(0.6475-0.7512)$ & $0.5613(0.5416-0.5810)$ & $0.7318(0.6780-0.7856)$ \\
New nodal staging system & $0.6993(0.6475-0.7510)$ & $0.5611(0.5415-0.5807)$ & $0.7310(0.6774-0.7846)$ \\
\hline
\end{tabular}

The $95 \%$ confidence interval is given in parentheses

AJCC American Joint Committee on Cancer

of patients with $\mathrm{T} 1$ cancer on the basis of a large sample and long-term results, and we examined these results in relation to the classifications in the sixth and seventh editions of the AJCC staging system. We found that these classifications were not well distributed in the survival curve. Hence, we developed a new classification- N1, one to five lymph node metastases; N2, six to ten lymph node metastases; and N3, more than ten lymph node metastases-and found that this classification gave satisfactory survival curves. However, we could not prove that the most recent TNM classification is not appropriate in regard to survival prediction using the $C$ index.
Our study had some limitations of note. This is a retrospective study. Lymph node metastasis is rare in EGC (12.1\% in our study). Furthermore, N2 or N3 cancers were very rare. Although we evaluated 2024 patients with EGC, 256 patients are really involved in the nodal group. So, the statistical power of our analysis was limited by the relatively small number of each TNM stage. Finally, our cutoff value of lymph node metastasis could not be high because lymph node metastasis was rare in EGC and the statistical power was not high. Therefore, the accuracy of this article still needs to be discussed. 
In conclusion, the classifications in the sixth and seventh editions of the AJCC staging system have a limitation for disease-related death from T1 gastric cancer (EGC). However, we could not prove that the most recent TNM classification (seventh edition of the AJCC staging system) is appropriate in regard to survival prediction.

\section{Compliance with ethical standards}

Conflict of interest The authors declare that they have no conflict of interest.

Ethical standards All procedures followed were in accordance with the ethical standards of the responsible committee on human experimentation (institutional and national) and with the Helsinki Declaration of 1964 and later versions. Informed consent or substitute for it was obtained from all patients for their being included in the study.

\section{References}

1. Kim CY, Lee SY, Yang DH. What is the prognosis for early gastric cancer with $\mathrm{pN}$ stage 2 or 3 at the time of pre-operation and operation. J Korean Gastric Cancer Assoc. 2006;6:114-9.

2. Fujii M, Sasaki J, Nakajima T. State of the art in the treatment of gastric cancer: from the 71st Japanese Gastric Cancer Congress. Gastric Cancer. 1999;2:151-7.

3. Adachi Y, Mori M, Maehara Y, Kitano S, Sugimachi K. Prognostic factors of node-negative gastric carcinoma: univariate and multivariate analyses. J Am Coll Surg. 1997;184:373-7.

4. Kubota H, Kotoh T, Masunaga R, Dhar DK, Shibakita M, Tachibana M, et al. Impact of screening survey of gastric cancer on clinicopathological features and survival: retrospective study at a single institution. Surgery. 2000;128:41-7.

5. Oliveira FJ, Ferrao H, Furtado E, Batista H, Conceicao L. Early gastric cancer: report of 58 cases. Gastric Cancer. 1998;1:51-6.
6. Ichiyoshi Y, Toda T, Minamisono Y, Nagasaki S, Yakeishi Y, Sugimachi K. Recurrence in early gastric cancer. Surgery. 1990;107:489-95.

7. Wu B, Wu D, Wang M, Wang G. Recurrence in patients following curative resection of early gastric carcinoma. J Surg Oncol. 2008;98:411-4.

8. Yamamoto M, Yamanaka T, Baba H, Kakeji Y, Maehara Y. The postoperative recurrence and the occurrence of second primary carcinomas in patients with early gastric carcinoma. J Surg Oncol. 2008;97:231-5.

9. Al-Refaie WB, Tseng JF, Gay G, Patel-Parekh L, Mansfield PF, Pisters PW, et al. The impact of ethnicity on the presentation and prognosis of patients with gastric adenocarcinoma. Results from the National Cancer Data Base. Cancer. 2008;113:461-9.

10. Nogueira C, Silva AS, Santos JN, Silva AG, Ferreira J, Matos E, et al. Early gastric cancer: ten years of experience. World J Surg. 2002;26:330-4.

11. Japanese Gastric Cancer Association. Japanese classification of gastric carcinoma-2nd English edition. Gastric Cancer. 1998;1:10-24.

12. Pencina MJ, D'Agostino RB. Overall $C$ as a measure of discrimination in survival analysis: model specific population value and confidence interval estimation. Stat Med. 2004;23:2109-23.

13. Folli S, Dente M, Dell'Amore D, Gaudio M, Nanni O, Saragoni L, et al. Early gastric cancer: prognostic factors in 223 patients. Br J Surg. 1995;82:952-6.

14. Otsuji E, Kuriu Y, Ichikawa D, Ochiai T, Okamoto K, Yamagishi $\mathrm{H}$. Prediction of lymph node metastasis by size of early gastric carcinoma. Hepatogastroenterology. 2007;54:602-5.

15. Sano T, Sasako M, Kinoshita T, Maruyama K. Recurrence of early gastric cancer. Follow-up of 1475 patients and review of the Japanese literature. Cancer. 1993;72:3174-8.

16. Maehara Y, Hasuda S, Koga T, Tokunaga E, Kakeji Y, Sugimachi K. Postoperative outcome and sites of recurrence in patients following curative resection of gastric cancer. Br J Surg. 2000;87:353-7.

17. Sakar B, Karagol H, Gumus M, Basaran M, Kaytan E, Argon A, et al. Timing of death from tumor recurrence after curative gastrectomy for gastric cancer. Am J Clin Oncol. 2004;27:205-9. 